\title{
Ultrarapid Inductive Rewarming of Vitrified Biomaterials with Thin Metal Forms
}

\author{
Navid Manuchehrabadi, ${ }^{1,2}$ Meng Shi, ${ }^{3,4}$ Priyatanu Roy, ${ }^{1}$ Zonghu Han, ${ }^{1}$ Jinbin Qiu, ${ }^{4,5}$ Feng Xu, ${ }^{4,5}$ \\ TIAN JIAN Lu, ${ }^{4,6}$ and JOHN BISCHOF ${ }^{1,2}$ \\ ${ }^{1}$ Department of Mechanical Engineering, University of Minnesota, 111 Church Street SE, Minneapolis, MN 55455, USA; \\ ${ }^{2}$ Department of Biomedical Engineering, University of Minnesota, 111 Church Street SE, Minneapolis, MN 55455, USA; \\ ${ }^{3}$ School of Energy and Power Engineering, Xi'an Jiaotong University, Xi'an 710049, People's Republic of China; ${ }^{4}$ Bioinspired \\ Engineering and Biomechanics Center (BEBC), Xi'an Jiaotong University, Xi'an 710049, People's Republic of China; ${ }^{5}$ The Key \\ Laboratory of Biomedical Information Engineering of Ministry of Education, School of Life Science and Technology, Xi'an \\ Jiaotong University, Xi'an 710049, People's Republic of China; and ${ }^{6}$ State Key Laboratory for Strength and Vibration of \\ Mechanical Structures, School of Aerospace, Xi'an Jiaotong University, Xi'an 710049, People's Republic of China
}

(Received 31 January 2018; accepted 25 May 2018; published online 19 June 2018)

Associate Editor Jennifer West oversaw the review of this article.

\begin{abstract}
Arteries with 1-mm thick walls can be successfully vitrified by loading cryoprotective agents (CPAs) such as VS55 $(8.4 \mathrm{M})$ or less concentrated DP6 (6 M) and cooling at or beyond their critical cooling rates of 2.5 and $40{ }^{\circ} \mathrm{C} / \mathrm{min}$, respectively. Successful warming from this vitrified state, however, can be challenging. For example, convective warming by simple warmbath immersion achieves $70{ }^{\circ} \mathrm{C} / \mathrm{min}$, which is faster than VS55's critical warming rate of $55^{\circ} \mathrm{C} / \mathrm{min}$, but remains far below that of DP6 $\left(185^{\circ} \mathrm{C} / \mathrm{min}\right)$. Here we present a new method that can dramatically increase the warming rates within either a solution or tissue by inductively warming commercially available metal components placed within solutions or in proximity to tissues with non-invasive radiofrequency fields $(360 \mathrm{kHz}, 20 \mathrm{kA} / \mathrm{m})$. Directly measured warming rates within solutions exceeded $1000{ }^{\circ} \mathrm{C} / \mathrm{min}$ with specific absorption rates $(\mathrm{W} / \mathrm{g})$ of 100,450 and 1000 for copper foam, aluminum foil, and nitinol mesh, respectively. As proof of principle, a carotid artery diffusively loaded with VS55 and DP6 CPA was successfully warmed with high viability using aluminum foil, while standard convection failed for the DP6 loaded tissue. Modeling suggests this approach can improve warming in tissues up to 4-mm thick where diffusive loading of CPA may be incomplete. Finally, this technology is not dependent on the size of the system and should therefore scale up where convection cannot.
\end{abstract}

Keywords-Vitrification, Rewarming, Ultrarapid warming, Nanowarming, Skin depth, RF heating, Tissue preservation.

Navid Manuchehrabadi and Meng Shi contributed equally to the work.

Address correspondence to Tian Jian Lu, Bioinspired Engineering and Biomechanics Center (BEBC), Xi'an Jiaotong University, Xi'an 710049, People's Republic of China and John Bischof, Department of Mechanical Engineering, University of Minnesota, 111 Church Street SE, Minneapolis, MN 55455, USA. Electronic mails: tjlu@mail.xjtu.edu.cn, bischof@umn.edu

\section{INTRODUCTION}

The use of low temperatures to indefinitely bank and store tissues for eventual transplantation is a main goal of the field of cryobiology. ${ }^{15,19,24}$ This approach, often termed cryopreservation, has been successfully used for long-term storage of cells, aggregates, and some smaller tissues. ${ }^{10,15,19,35}$ However, the availability of many tissues and almost all organs is limited due to several important bottlenecks, including the need for faster warming in larger and thicker tissue systems. $^{11,12,16,18}$

One of the best options for cryopreservation of tissues and larger systems involves vitrification or storage in a glassy state that avoids ice crystal damage. This requires tissues and other biomaterials (i.e., suspensions) to be loaded with cryoprotective agents (CPAs) to block ice crystal formation during cooling to temperatures below the glass transition temperature of the CPA, usually $-140{ }^{\circ} \mathrm{C} .{ }^{10}$

CPA toxicity can generally be avoided by using lower concentration CPAs, but this means that the critical warming rate $(\mathrm{CWR})$ increases from $55^{\circ} \mathrm{C} / \mathrm{min}$ for $8.4 \mathrm{M} \mathrm{VS55}$ to $185^{\circ} \mathrm{C} / \mathrm{min}$ for $6 \mathrm{M} \mathrm{DP6} 6^{7,22,34}$ to avoid devitrification during warming. $7,8,18,22,34$ Similarly, as tissue thickness increases, longer loading time (hours) would be needed to equilibrate the distrubution of CPA in the tissue. As this time increases beyond normal loading times (4-5 steps of roughly $15 \mathrm{~min}$ each), the potential for toxicity and therefore lower viability at the edge of the tissue being loaded will in- 
crease. Therefore, all tissues (thick or thin) are loaded with the least amount of CPA over the least time to avoid toxicity. As a result, there will always be a lower concentration in the center of the loaded tissue which, especially in the case of thicker tissue, will necessitate faster rates of warming to successfully avoid crystallization damage.

To address these issues, microwave warming $9,17,23,25,26,36$ and nanowarming with nanoparticles $^{8,18}$ have been proposed to achieve faster warming of tissues than convection. Microwave warming, however, can be non-uniform, resulting in "hot spots" which can drive subsequent cracking and/or thermal runaway. Moreover, its application varies by size and shape within a system..$^{3,4,9,25}$ Alternatively, nanowarming adds biocompatible magnetic (iron oxide) nanoparticles to the CPA prior to vitrification and storage. Rewarming is achieved within an electromagnetic coil producing a uniform radiofrequency field that inductively heats the nanoparticles and then, by extension, the whole system. ${ }^{8,18}$ This technology has achieved uniform warming rates up to $100{ }^{\circ} \mathrm{C} / \mathrm{min}$ for porcine tissues regardless of volume, ${ }^{18}$ and has successfully warmed $\sim 1 \mathrm{~mm}$ arteries loaded with VS55 in 1-50 $\mathrm{mL}$ systems. Nevertheless, the rates necessary to successfully warm DP6 solutions, loaded arteries, or thicker arteries (i.e., aorta) are difficult to achieve with achievable rates from convection or nanowarming.

In this study, we developed an ultra-rapid volumetric heating method to heat solutions or tissue systems at $\geq 1000{ }^{\circ} \mathrm{C} / \mathrm{min}$, which is a rate that is an order of magnitude faster than convection, nanowarming or the CWR of DP6 and VS55. ${ }^{8,18,22}$ Solutions or tissues were vitrified and placed in contact with thin metal forms (foam, foil, or mesh) as shown in Fig. 1. The alternating magnetic field induced eddy currents in the metal with concurrent resistive losses that heated the sample from within (Figure S2A). As a demonstration of use, this approach was then used to successfully rewarm DP6 loaded carotid arteries where convection failed.

\section{MATERIALS AND METHODS}

\section{Preparation of Thin Metal Forms: Foam, Foil, and Mesh}

In this study, metal forms consisted of copper foam (YiYang Foammetal New Materials Co., Ltd., Hunan, China), $100-\mu \mathrm{m}$ thick aluminum foil (Reynolds Wrap, Lake Forest, IL), and $500-\mu \mathrm{m}$ thick nitinol mesh (Boston Scientific, Saint Paul, MN) structures as shown in Tables 1 and 2. These choices were made to test a range of metals with variable electrical properties and ease of shaping.

Preliminary tests were performed with copper foams with 20 pores per inch and 89 percent porosity. These were formed by wire electrical discharge machining into a cylindrical shape with diameter and height of 9.8 and $23 \mathrm{~mm}$, respectively. Two fluoroptic probes (Qualitrol Company LLC, Fairport, NY) were used to monitor the temperature at the center and edge of the foam with a vertical position of $30 \mathrm{~mm}$ from the top of a $1.8-\mathrm{mL}$ cryovial. The metal foams were placed in the cryovial (Cole Parmer, Vernon Hills, IL), and CPA was added until reaching $1.8-\mathrm{mL}$ volume (Fig. 2a). The metal foil and mesh were formed into a cylindrical shell (annulus) shape with properties mentioned in Table 2. Cooling and heating under these conditions without the presence of an artery or tissue are understood to represent limiting cases.

\section{Cooling Approaches}

The two CPAs, VS55 and DP6, have very different critical cooling rates, so two separate cooling protocols were used to achieve vitrification at rates that exceed the critical cooling rate (Fig. 2b).

\section{Fast and Direct Cooling (DP6)}

DP6 solution requires a high critical cooling rate $\left(-40{ }^{\circ} \mathrm{C} / \mathrm{min}\right)$ for vitrification. To achieve this, the 1.8$\mathrm{mL}$ cryovials loaded with the metal and CPA were lowered into a large flask filled with liquid nitrogen and held in the vapor phase $\left(-160{ }^{\circ} \mathrm{C}\right)$ just above the surface of the liquid. Temperature was monitored using two fluoroptic probes placed at the center and edge of the vial (Qualitrol Company LLC, Fairport, NY) connected to a T/GUARD 405 temperature monitoring system (Neoptix, Canada). One of the probes measured the centerline temperature of the CPA solution in the vial while the other was placed on the outside near the vial wall. When the center reached $-115^{\circ} \mathrm{C}$, the vial was allowed to anneal by taking the cryovial out of the flask for 5-7 s to allow the center and the edge of the CPA inside the cryovial to equilibrate and stabilize. By performing this just above the glass transition temperature $\left(-123{ }^{\circ} \mathrm{C}\right.$ for $\operatorname{VS} 55^{20}$ and $-119^{\circ} \mathrm{C}$ for DP $\left.6{ }^{22}\right)$, residual thermal stresses are reduced, thereby lowering the chance of cracking when the sample transitions into a glass. Finally, the samples were cooled to $-140{ }^{\circ} \mathrm{C}$, and monitored for any cracking (more than $90 \%$ of samples achieved vitrification without cracking). A number of these successfully vitrified samples were then either placed in the RF system or convective water bath to compare warming processes. 
(a)

Tissue procurement

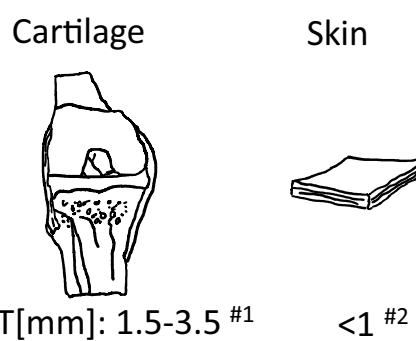

(c) Traditional convection

$h, T_{\text {env }}$

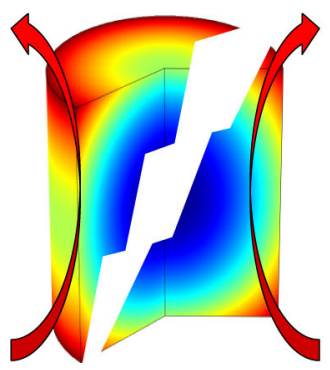

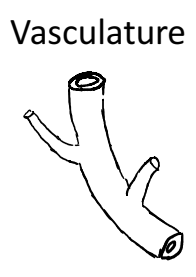

$0.5-1.5 \# 3$ (b) Choice of thermal seed
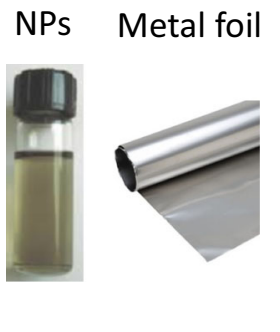

Metal foam

Metal mesh

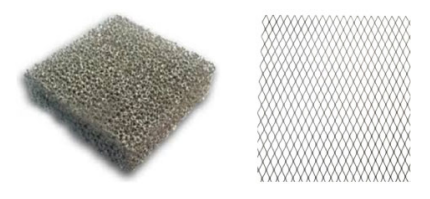

RF warming
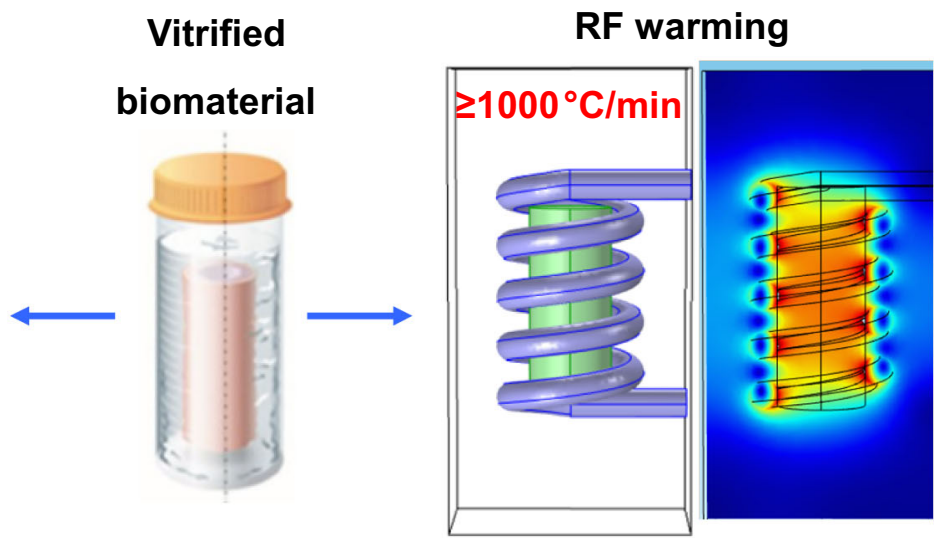

FIGURE 1. Schematic of planar and annular tissues that can benefit from the ultrarapid warming method. Ultrarapid warming can be deployed in solutions or tissues with several $\mathrm{mm}$ thickness, especially with planar or cylindrical geometries (a). Both ultrarapid warming (with foam/foil/mesh) and nanowarming (with nanoparticles) relies on coupling the alternative magnetic field to the metallic substance, but an order of magnitude higher rate is possible with ultrarapid warming approach (b). Both approaches ensure homogenous and fast warming rates to avoid devitrification and cracking can occur with convection (c). The references in (a) are Refs. 18, 27, and 28.

TABLE 1. Thermal and electrical properties of metals used in study. Theoretical SAR is calculated for a solid rod with the diameter of $0.965 \mathrm{~mm}$ heated in an RF system working at frequency of $f=360 \mathrm{kHz}$ and magnetic field intensity of $H_{0}=20 \mathrm{kA} / \mathrm{m}$.

\begin{tabular}{|c|c|c|c|c|c|c|c|}
\hline Metal & $\begin{array}{c}\text { Skin depth }(\delta) \\
(\mu \mathrm{m})\end{array}$ & $\begin{array}{l}\text { Resistivity }\left(\rho_{\mathrm{e}}\right) \\
(\Omega . \mathrm{m})\end{array}$ & $\begin{array}{l}\text { Electrical conductivity } \\
(\sigma)(\mathrm{S} / \mathrm{m})\end{array}$ & $\begin{array}{l}\text { Relative permeabil- } \\
\text { ity }\left(\mu_{\mathrm{r}}\right)(-) \\
\end{array}$ & $\begin{array}{l}\text { Density }(\rho) \\
\quad(\mathrm{g} / \mathrm{cc})\end{array}$ & $\begin{array}{c}\text { Volumetric SAR } \\
\left(\mathrm{W} / \mathrm{cm}^{3}\right)\end{array}$ & $\begin{array}{l}\mathrm{SAR}_{\text {The }} \\
(\mathrm{W} / \mathrm{g})\end{array}$ \\
\hline Copper & 140 & $1.68 \times 10^{-8}$ & $5.96 \times 10^{7}$ & 0.9999 & 8.96 & 936 & 105 \\
\hline Aluminum & 108 & $2.82 \times 10^{-8}$ & $3.50 \times 10^{7}$ & 0.9994 & 2.70 & 1221 & 450 \\
\hline Nitinol & 760 & $82 \times 10^{-8}$ & $0.12 \times 10^{7}$ & 1.0020 & 6.50 & 6550 & 1000 \\
\hline
\end{tabular}

Slow and Controlled Cooling (VS55)

VS55 has a lower critical cooling rate $\left(-2.5^{\circ} \mathrm{C} /\right.$ min) than DP6, so a multi-flask cooling method for a 1.8 -mL system was used as previously described. ${ }^{8,18}$ In brief, the cryovials were placed in a series of concentric, successively larger containers, with liquid nitrogen filling the outside of most containers. This layering of containers provided thermal barriers for heat transfer between the liquid nitrogen and the cryovial and slowed down the heat transfer rate. To monitor the temperature during cooling, two fluoroptic probes were positioned in the center and on the edge of the cryovial as described in the DP6 cooling section above. Once the center reached $-115^{\circ} \mathrm{C}$, the sample was annealed for 5-7 s and finally cooled to $-140{ }^{\circ} \mathrm{C}$. The vast majority of these samples were vitrified and noncracked. A number of these were then placed either in an RF system or convective water bath to compare warming processes.

\section{Warming Approaches}

\section{Convective Warming}

The vitrified samples were transferred from the liquid nitrogen container and immersed into a $37{ }^{\circ} \mathrm{C}$ water bath while the temperature variation was recorded using fluoroptic probes placed in the middle and edge of the sample (Fig. 2c-top). 
TABLE 2. Physical properties of copper foam, aluminum foil and nitinol mesh.

\begin{tabular}{|c|c|c|c|c|c|}
\hline Thickness $(\mu \mathrm{m})$ & Mass (g) & Width (cm) & Length $(\mathrm{cm})$ & Volume $\left(\mathrm{cm}^{3}\right)$ & Density $\left(\mathrm{g} / \mathrm{cm}^{3}\right)$ \\
\hline 200 & 2.50 & 0.965 & 2.29 & 1.67 & 0.98 \\
\hline 100 & 0.79 & 0.940 & 2.34 & 1.62 & 0.48 \\
\hline 500 & 0.77 & 0.050 & 2.25 & 0.12 & 0.50 \\
\hline $\mathrm{HR}\left({ }^{\circ} \mathrm{C} / \mathrm{min}\right)$ & $\mathrm{SAR}_{\operatorname{Exp}}\left(\mathrm{W} / \mathrm{cm}^{3}\right)$ & \multicolumn{2}{|c|}{ Metal type and structure } & $\operatorname{SAR}_{\operatorname{Exp}}(\mathrm{W} / \mathrm{g})$ & $\mathrm{SAR}_{\text {Exp } / \mathrm{SAR}_{\text {The }}(\%)}$ \\
\hline 1200 & 80 & Copper foam & & 82 & 80 \\
\hline 1000 & 200 & Aluminum foil & & 415 & 92 \\
\hline 330 & 480 & Nitinol mesh & & 960 & 96 \\
\hline
\end{tabular}

Heating rates and experimental SARs are calculated from the linear portion of the heating profile.

(a)

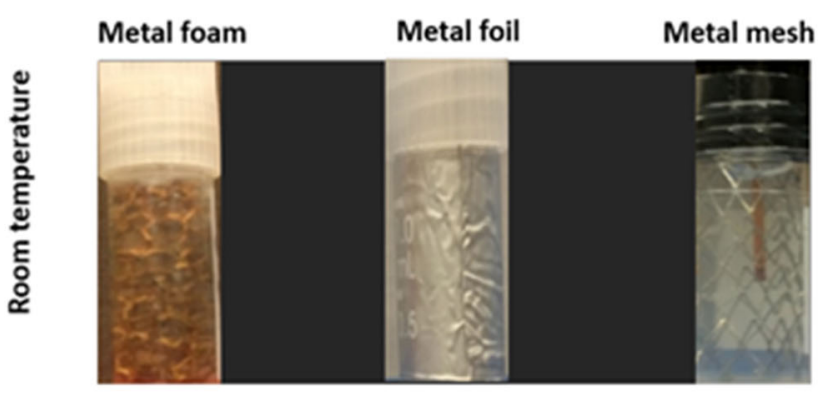

(b)

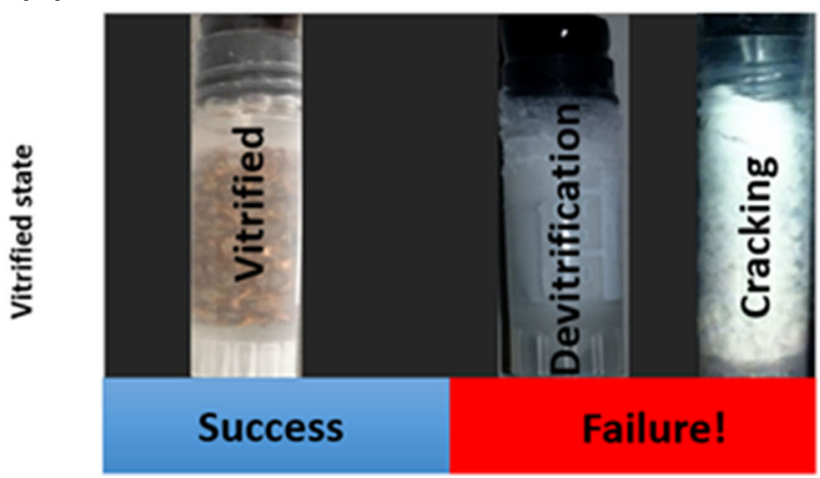

(c) Warming
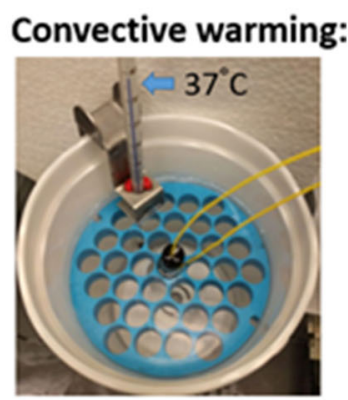

Ultrarapid inductive RF warming:

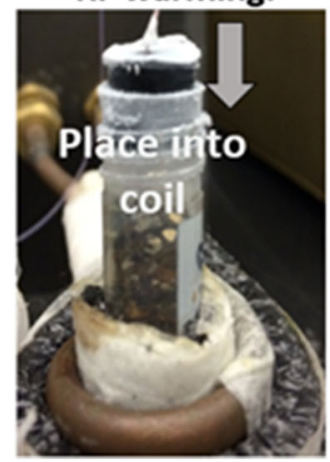

FIGURE 2. Ultrarapid warming steps using metal forms (foams, foils or meshes). (a) Loading of VS55 or DP6 in a 1.8-mL cryovial containing copper foams, aluminum foil or nitinol mesh at room temperature. (b) Success and failure of cooling solutions to subglass transition temperature $-140^{\circ} \mathrm{C}$. (c) Rewarming vitrified solutions by convection or inductive RF heating (ultrarapid warming).

\section{Ultrarapid Warming}

As shown in Fig. 2c-bottom, 1.8-mL vitrified samples consisting of metal (foam, foil and mesh) loaded in DP6 and VS55 at $-140{ }^{\circ} \mathrm{C}$ were quickly transferred into the coil of a 1-kW Hotshot inductive heating system. The RF system has a 2.5-turn watercooled copper coil (Ameritherm Inc., Scottsville, NY), and experiments were carried out at a magnetic field strength of $20 \mathrm{kA} / \mathrm{m}$ (peak, volume-averaged field 
strength) and frequency of $360 \mathrm{kHz}$. The cryovial was placed within a Styrofoam container within the coil to lessen direct loss to the environment. The time of RF exposure was characterized for each case of metal forms (copper foam, aluminum foil and nitinol mesh) to ensure the final temperature of $-20^{\circ} \mathrm{C}$ (near melt of CPA) was reached prior to turning off the field. Typically, the temperature would then continue to rise more slowly to room temperature prior to any further studies. To assess the warming efficacy, we considered warming rates from $-140{ }^{\circ} \mathrm{C}$ vitrified state to $-20^{\circ} \mathrm{C}$, where CPA is liquid and the low temperature leads to a reduction in toxicity. We noted that the resulting heat generation or specific absorption rate (SAR) depends on the metal type, shape, structure, weight, volume and orientation of placement in RF coil. Therefore, samples from different metal forms warm at different rates and lead to different volumetric SAR $\left(\mathrm{W} / \mathrm{cm}^{3}\right)$ or mass-based SAR $(\mathrm{W} / \mathrm{g})$ as shown in Table 2. The sample temperature was achieved continuously at a frequency of $5 \mathrm{~Hz}$ by means of fluoroptic probes.

\section{Viability Studies}

For viability experiments, we chose to work with aluminum foil warming due to ease of deployment in DP6 and VS55 samples and compared this to convective warming controls. Porcine arteries were obtained postmortem from skeletally immature domestic Yorkshire cross farm pigs $(65-80 \mathrm{~kg}$, aged 1618 weeks). Arteries were removed within $30 \mathrm{~min}$ of death following Institutional Animal Care and Use Committee (IACUC) approved protocols at University of Minnesota. The animals were sacrificed as part of other IACUC approved studies at the Visible Heart $\mathrm{Lab}$ and the arteries were considered bona fide excess. Arteries were submerged in a Krebs-Henseleit buffer and placed on ice before being transported to our laboratory. Upon receipt (hours later), arteries were dissected to reproducible segments $\sim 1-\mathrm{cm}$ height. Fresh artery segments were rinsed with growth media [Dulbecco's modified Eagle's medium (Thermo Fisher) with $1 \%$ antibiotic-antimycotic (Thermo Fisher)], and cleared of fatty tissue. Carotid arteries were sectioned into $1 \mathrm{~cm}$-long segments with inner diameters of 4 $6 \mathrm{~mm}$ and wall thicknesses 1-2 mm. Experiments were carried out on several independent days with 3-4 arteries per test and 4-6 slices per artery for ultrarapid warming and convective warming tests.

Viability was assessed by incubation with $10 \%$ alamarBlue (Thermo Fisher) media solution at $37{ }^{\circ} \mathrm{C}$ for $3 \mathrm{~h}$ before (control) and after any warming experiments. Fluorescence was read on a plate reader (Synergy HT, BioTek) at $590 \mathrm{~nm}$ from an aliquot of the media to establish a baseline. For arteries undergoing ultrarapid or convective methods, tissues were stepwise loaded with CPA as previously published. ${ }^{1,18}$ Once the arteries experienced the final step of loading at full-strength VS55 or DP6, the aluminum foil was placed against the interior (i.e., luminal) and exterior artery walls to create a sandwich, and the remainder was filled with the CPA. All samples were successfully vitrified by the protocols explained above and equilibrated at $-140{ }^{\circ} \mathrm{C}$ prior to transfer to the warming apparatus.

Ultrarapid rewarming was achieved by either inductive RF warming at $20 \mathrm{kA} / \mathrm{m}, 360 \mathrm{kHz}$, or by convective warming using $37^{\circ} \mathrm{C}$ water bath immersion, considered here as a gold- standard control. After warming to room temperature $\left(18-20^{\circ} \mathrm{C}\right)$, the VS55 and DP6 was step-wise removed as previously reported. ${ }^{1}$ After the removal of the CPA, the tissue segments were sectioned into small pieces and incubated with fresh media at $37^{\circ} \mathrm{C}$ for one hour (recovery) and then incubated with $10 \%$ alamarBlue for $3 \mathrm{~h}$ and compared with fresh controls. The viability of each tissue piece was normalized to fresh control. Raw results are presented as the mean \pm standard error of relative fluorescence units (RFU) after correction to $\mathrm{RFU} / \mathrm{mg}$ dry weight prior to normalization.

\section{Heat Transfer Modeling}

Temperature modeling was approached using a 2-D cylindrical energy equation for solving the heat-transfer problem. Different solid domains were assigned as shown in Fig. 3 for metal, cryovial and tissue (when present), and the heat diffusion equation was solved:

$$
\frac{1}{r} \frac{\partial}{\partial r}\left(k r \frac{\partial T}{\partial r}\right)+\frac{\partial}{\partial z}\left(k \frac{\partial T}{\partial z}\right)+\mathrm{SAR}=\rho c_{\mathrm{p}} \frac{\partial T}{\partial t},
$$

where $k$ represents the thermal conductivity, $\rho$ the density, $c_{\mathrm{p}}$ the specific heat capacity, $T$ the temperature, and SAR $\left(\mathrm{W} / \mathrm{m}^{3}\right)$ the volumetric heat generation rate from the metals due to RF heating. Initial and boundary conditions and other parameters are listed in the Supplemental Material under "heat-transfer modeling" and are listed for specific cases in Fig. 3.

The solution domain consists of two concentric cylinders. In case of metal foam (Fig. 3a), the inner cylinder $\Omega_{1}$ is made up of CPA and foam. Thermal properties for the different domains are listed in Table S2A. In the case of CPA and foam in the middle of the cylinder, the properties are estimated by mass averaging using this equation:

$$
X_{\text {effective }}=\phi X_{\mathrm{CPA}}+(1-\phi) X_{\text {metal }},
$$

where $X_{\mathrm{CPA}}$ and $X_{\text {metal }}$ are the corresponding properties for the pure CPA and pure metal, respectively, and 

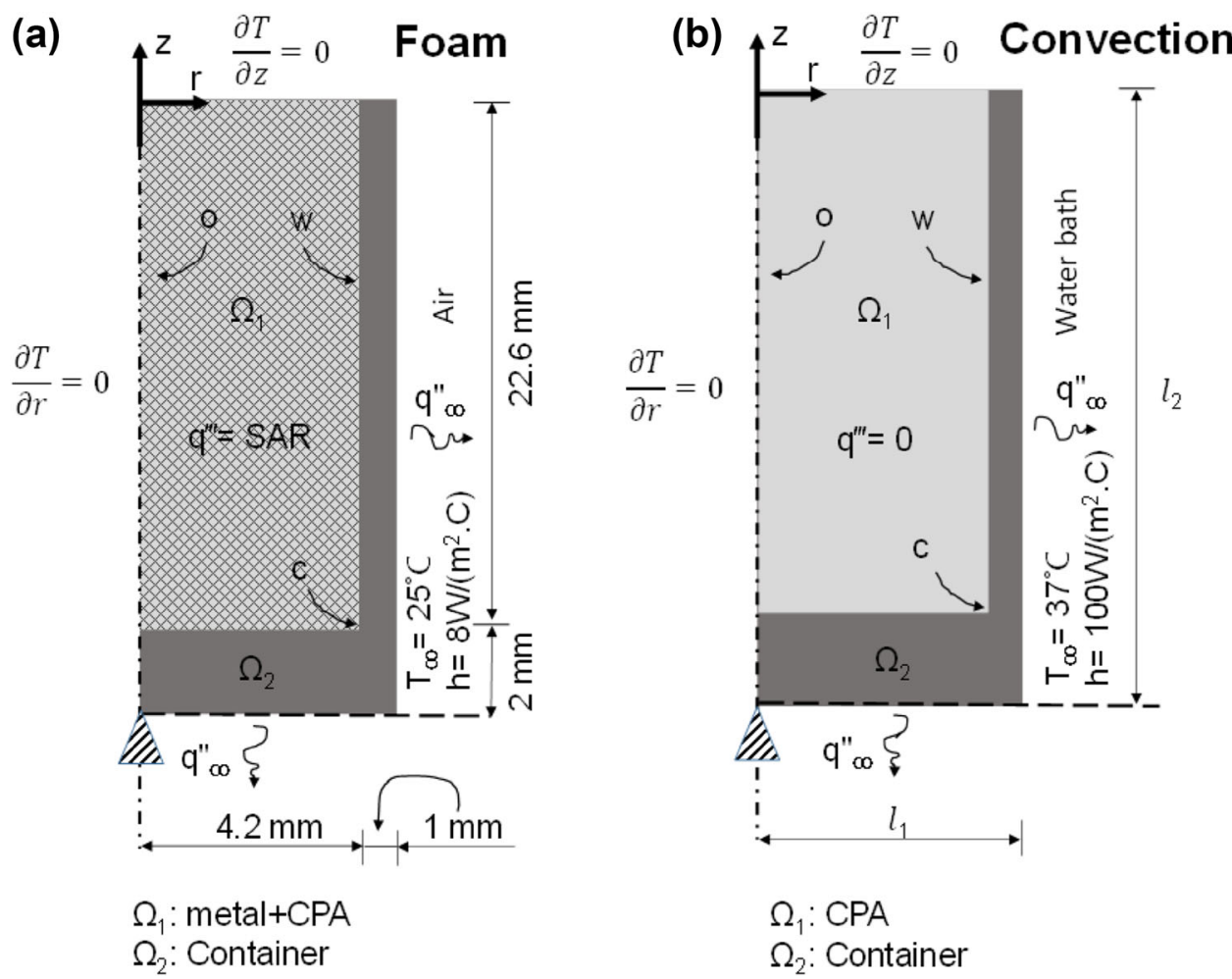

FIGURE 3. Schematic of the combined thermal and solid mechanics modeling. Boundary conditions and initial conditions are given for both ultrarapid warming of solutions using foam (a) and convective warming in water bath (b).

$\phi$ is the mass porosity of the metal foam. Volumetric heat generation is confined in the domain $\Omega_{1}$, and domain $\Omega_{2}$ mimics the polypropylene cryovial.

Figure $3 \mathrm{~b}$ describes the case of convective warming. In this model, the domain $\Omega_{1}$ consists of only CPA with no internal heat source, and warming is achieved only by boundary heating. The boundary conditions and initial condition for the heat-transfer problem are also indicated in Fig. 3. In both Figs. 3a and 3b, the top and left (symmetry) boundaries are assigned adiabatic conditions, while the bottom and right side of the container are assigned convective conditions. The free convection heat transfer coefficient in air (Fig. 3a) was taken as $8\left(\mathrm{~W} /\left(\mathrm{m}^{2} \cdot \mathrm{K}\right)\right)$ based on an empirical correlation from Incropera and DeWitt, ${ }^{14}$ whereas in water (Fig. 3b) it is assumed to be $100\left(\mathrm{~W} /\left(\mathrm{m}^{2} \cdot \mathrm{K}\right)\right)$ based on the ability to fit the experimentally determined convective heating response shown in Fig. 4c.

\section{Solid Mechanics Modeling}

While the heat transfer is unaffected by solid mechanics, the inverse is not true. Specifically, the mechanical response of the material is driven by thermal strain caused by temperature distribution within the domains as discussed in detail in the Supplemental
Material. To assess this coupling, mechanical and thermal properties were used in simulations as listed in the supplementary Table S2A. ${ }^{5,6,33}$ The CPA in domain $\Omega_{1}$ was modeled as a viscoelastic linear Maxwell fluid with a single-branch spring-dashpot behavior. ${ }^{32}$ The viscosity of the fluid increases as per supplementary Table S2B with drop in temperature until the fluid behaves as a solid at close to its glass-transition temperature. The total strain rate is calculated as the sum of elastic, creep, and thermal strain rates. ${ }^{5,29}$

$$
\dot{\varepsilon}=\dot{\varepsilon}_{\text {creep }}+\dot{\varepsilon}_{\text {elastic }}+\dot{\varepsilon}_{\text {thermal }}
$$

Domain $\Omega_{2}$ was the container, and it was set to act as an elastic solid over the temperature range considered. As shown in Figs. 3a and 3b, two different geometries were used corresponding to metal foam + CPA and CPA-only cases. The bottom center of the cylinder was used as a pinned boundary condition, while all other boundaries could move freely. Here, the shear stress is assumed to be negligible, and since the circumferential stress is much smaller than axial stress, ${ }^{5}$ it is not considered in the modeling. The commercial FEA package COMSOL Multiphysics was used for all the numerical heat and mechanics based simulations. In all cases, numerical stability and con- 
(a) Controlled cooling (VS55)
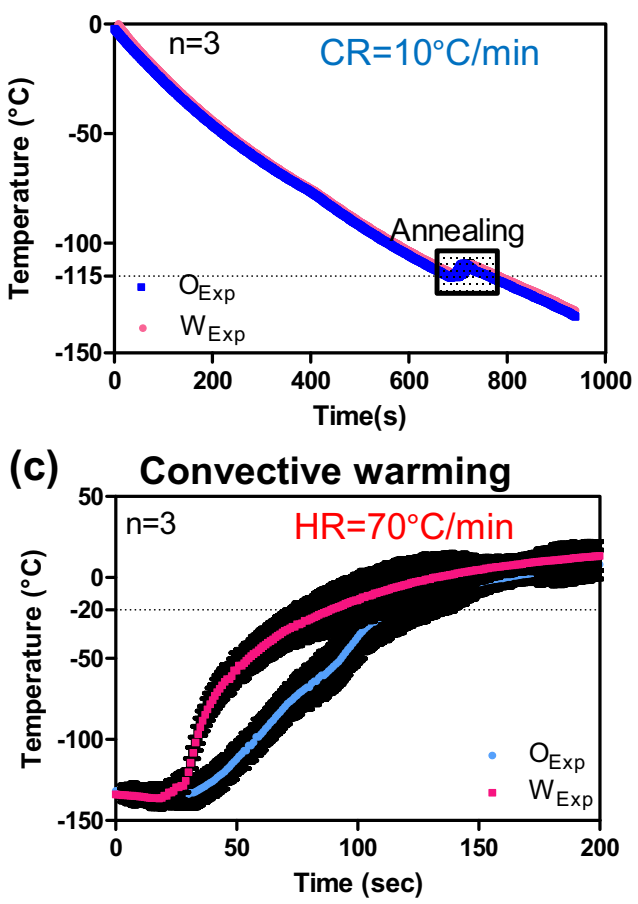

(b) Direct cooling (DP6)
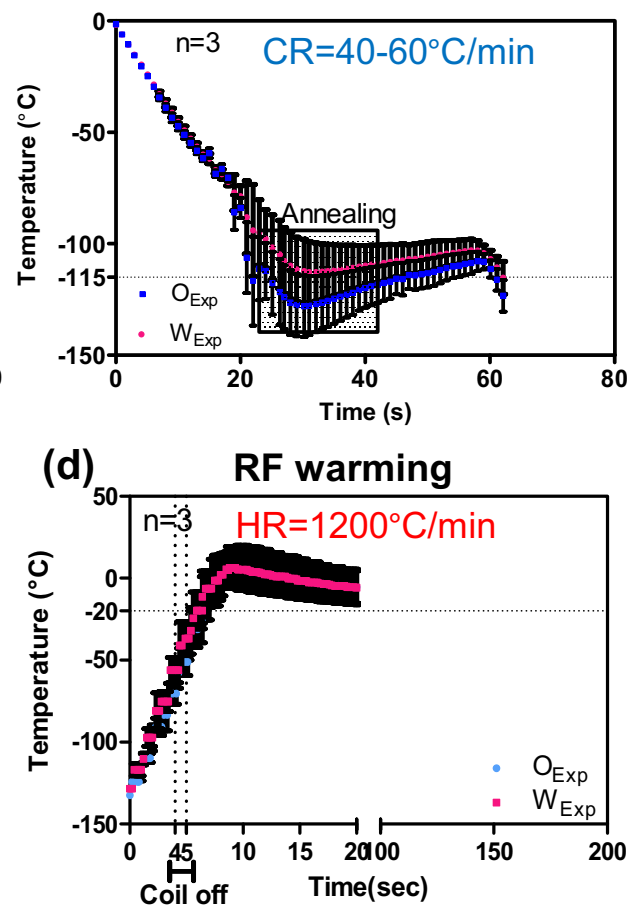

FIGURE 4. Experimental measurement of cooling and warming rates of vitrified vials. The cooling response of CPA and metal implanted cryovials are shown for VS55 (a) and DP6 (b). The respective rates of 10 and $40-60^{\circ} \mathrm{C} / \mathrm{min}$ exceed the critical cooling rates needed for VS55 $\left(2.5^{\circ} \mathrm{C} / \mathrm{min}\right)$ and DP6 $\left(40^{\circ} \mathrm{C} / \mathrm{min}\right)$. The warming responses during convection (c) and ultrarapid warming (d) are shown to achieve rates of 70 and $1200{ }^{\circ} \mathrm{C} / \mathrm{min}$, respectively. In (d), the RF coil was shut down at $-50^{\circ} \mathrm{C}$ to avoid overheating the sample.

vergence were ensured as further mesh reduction and discretization left the solution unchanged.

\section{Diffusional (CPA) Loading Model}

To model CPA loading, a 1D cylindrical annulus model of mass (i.e., CPA) diffusion based on Fick's 2nd Law, was applied with the concept that the CPA concentration, $C$, is governed by an effective diffusivity, $D\left(\mathrm{~m}^{2} / \mathrm{s}\right)$ in the tissue:

$$
\frac{1}{D} \cdot \frac{\partial C}{\partial t}=\frac{1}{r} \cdot \frac{\partial}{\partial r}\left(r \cdot \frac{\partial C}{\partial r}\right)
$$

with the boundary conditions and initial conditions as noted in Supplemental Methods. The method of separation of variables (analytical closed form) was used to obtain an exact solution for $C(r, t)$ as shown in the Supplemental Material. This closed-form solution was then plotted and visualized using MATLAB (MathWorks).

The value of diffusivity was estimated by fitting the theoretical curve to historical experimental data for VS55 loading into a carotid artery. ${ }^{18}$ More specifically, the boundary conditions were normalized with respect to the external CPA solution concentration at the first 18-min time step. The coefficient of determination, $R^{2}$, was used to assess how well the model was able to predict the experimental data. The value of $R^{2}$ was estimated as:

$$
R^{2} \equiv 1-\frac{\sum_{i}\left(y_{i}-f_{i}\right)^{2}}{\sum_{i}\left(y_{i}-\bar{y}\right)^{2}},
$$

where $y_{\mathrm{i}}$ is the experimental data, $f_{\mathrm{i}}$ is the theoretical value for the same radius, $\bar{y}$ is the average of experimental data. The range of $R^{2}$ is from 0 to 1 , with values closer to 1 indicating a better fit of the model to the data.

\section{RESULTS}

Figures $4 \mathrm{a}$ and $4 \mathrm{~b}$ and the images in Fig. 2 demonstrate that we can exceed the critical cooling rates of VS55 $\left(2.5^{\circ} \mathrm{C} / \mathrm{min}\right)$ and DP6 $\left(40{ }^{\circ} \mathrm{C} / \mathrm{min}\right)$ to achieve vitrified solutions as shown by the clarity of the solution and absence of cracks. Cooling rates measured were $10{ }^{\circ} \mathrm{C} / \mathrm{min}$ for VS55 and $40-60{ }^{\circ} \mathrm{C} / \mathrm{min}$ for DP6. Further, the slower VS55-controlled cooling method and the metal foam samples show minimal thermal gradients in the sample (Fig. 4a). Both samples were annealed at roughly $-115^{\circ} \mathrm{C}$, which is just 
(a) Convective warming

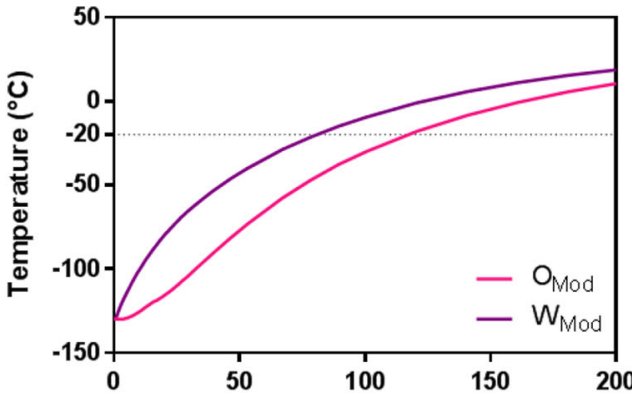

Time (sec)

(c)

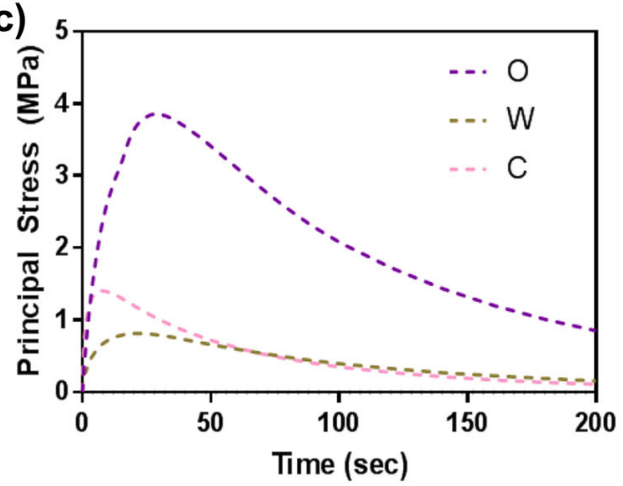

(b)
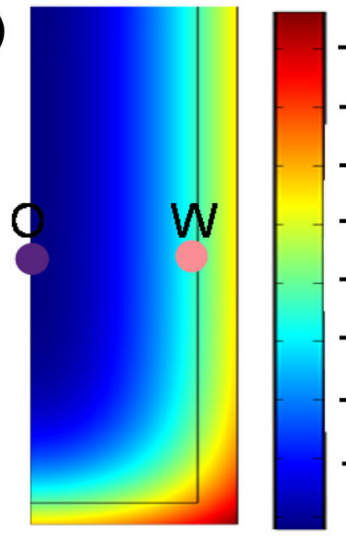

(d)

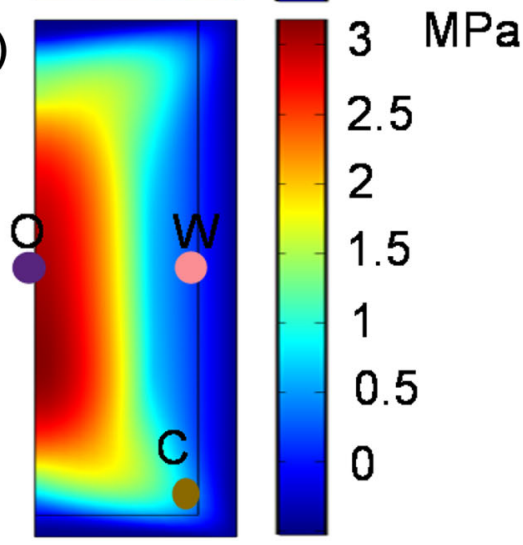

FIGURE 5. Computational thermal and mechanical stress analysis of convective warming. The simulated thermal (A and B) and stress responses $(C$ and $D)$ to $37^{\circ} \mathrm{C}$ water bath convective warming are shown. The maximum thermal gradient of $35{ }^{\circ} \mathrm{C}$ during convection results in thermal stress of $\sim 4 \mathrm{MPa}$, which exceeds the yield stress of $3.2 \mathrm{MPa}^{34}$ at the central point $\mathrm{O}$ along the axis of symmetry (C and D).

above the glass-transition temperatures of $-123{ }^{\circ} \mathrm{C}$ for VS55 $5^{20}$ and $-119{ }^{\circ} \mathrm{C}$ for DP6. ${ }^{34}$

Figures $4 \mathrm{c}$ and $4 \mathrm{~d}$ show an experimental comparison of inductive and convective warming of these vitrified materials from $-140{ }^{\circ} \mathrm{C}$, respectively. Warmbath immersion leads to convective rates up to $70{ }^{\circ} \mathrm{C} /$ min while inductive heating achieves $\geq 1200{ }^{\circ} \mathrm{C} / \mathrm{min}$ reaching $-20{ }^{\circ} \mathrm{C}$ in seconds. Indeed, it was necessary to shut the RF coil off at $-50{ }^{\circ} \mathrm{C}$ to avoid overheating of the sample (Fig. 5d). Temperature profiles at the center or origin $(\mathrm{O})$ to wall $(\mathrm{W})$ are similar for ultrarapid warming; however, a significant gradient is shown in the convective water bath (Fig. 4c). These results show our ability to exceed CWR of DP6 and VS55 by ultrarapid warming of copper foams. Similar measurements showing our ability to exceed CCR and CWR were made for other metals in VS55 as shown in the Supplemental Material and summarized in Table 2 and Figure S2.

The predicted thermal and mechanical response of the systems during convective and inductive ultrarapid warming are shown in Figs. 5 and 6 respectively. For instance, there is a maximum thermal gradient of $35^{\circ} \mathrm{C}$ in a convective water-bath method (Figs. 5a and 5b), resulting in thermal stress beyond the yield stress, specifically at the center or origin of $\sim 4 \mathrm{MPa}$, which will likely lead to failure by cracking (Figs. $5 \mathrm{c}$ and $5 \mathrm{~d}$ ). On the other hand, the computed thermal response (Figs. 6a and 6b) compares favorably to the experimental warming profiles (Fig. 4d) of a metal foam heating with RF. Figures $6 \mathrm{c}$ and $6 \mathrm{~d}$ illustrate the corresponding thermomechanical stress response. The positive sign in Fig. 6c represents tension, and the negative sign represents compression in a biomaterial. Note that a vitrified biomaterial would fail at much lower tension than compression, so we look for areas where the positive stress is maximum (e.g., at the wall (W) in Fig. 6d). The simulated stress level is $40 \%$ less than the critical yield stress of $3.2 \mathrm{MPa}$, suggesting that failure by cracking is unlikely.

Even with an order-of-magnitude higher warming rate, this technique will still be limited by the amount of CPA that can be effectively loaded into the artery. To address this, VS55 diffusive loading into carotid arteries was studied (Figs. 7a-7c), and warming of CPA loaded arteries of variable thickness was attempted experimentally (Fig. 7d). By matching the diffusion equation to the experimental data at $18 \mathrm{~min}$, 
(a)

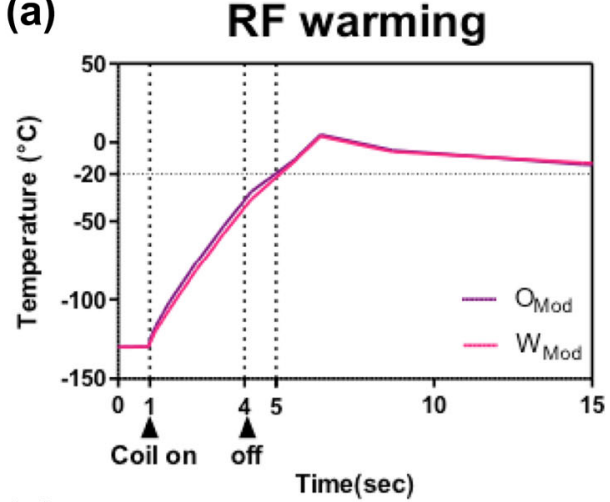

(c)

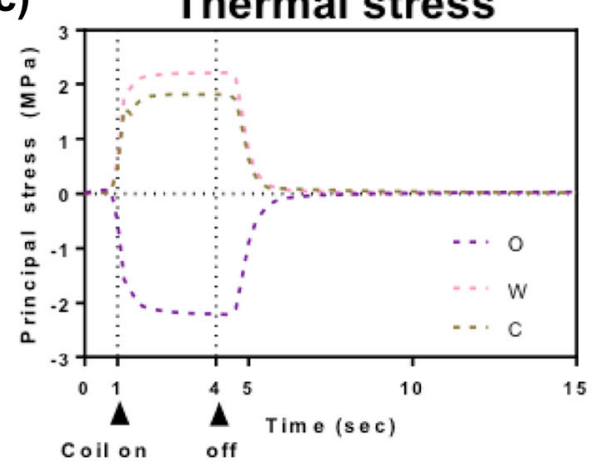

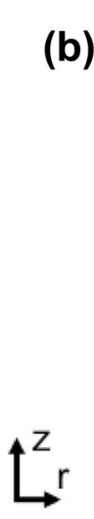

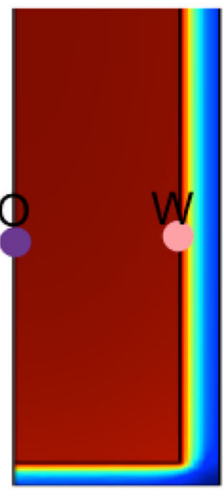

(d)

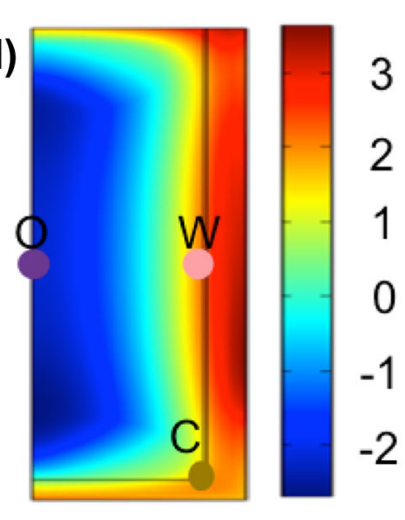

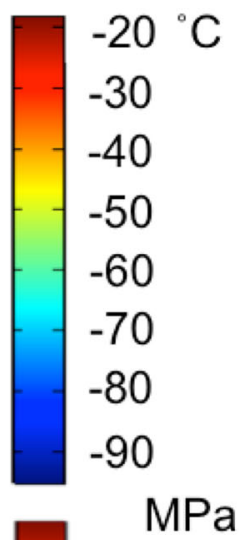

3

2

1

0

$-1$

$-2$

FIGURE 6. Computational thermal and mechanical stress analysis during ultrarapid warming. The simulated thermal (a and b) and stress responses (c and d) to ultrarapid heating are shown. The positive values in (c) represent tension, while negative values imply compression in the system. Note that the vitrified system would fail at much lower tension than compression; therefore, failure may occur in areas where the positive stress is maximum (e.g., a wall) but still below the yield stress of $3.2 \mathrm{MPa}^{34}$ (d).

a mass diffusivity of $3.18 \times 10^{-11} \mathrm{~m}^{2} / \mathrm{s}$ was extracted as shown in (Fig. 7a). The final $R^{2}$ for the data set at $4{ }^{\circ} \mathrm{C}$ at 18 min was 0.94 indicating a good fit. ${ }^{18}$ To assess the impact of differential loading experimentally Fig. $7 \mathrm{~b}$ shows loading of CPA into a thin carotid artery. Clearly, the viability drops as the amount of CPA that can be delivered to the tissue center is reduced in the aorta. Using the diffusion loading model, spatial and temporal distribution of VS55 concentration within the carotid artery is shown to reach more than $60 \%$ in the center after $60 \mathrm{~min}$ in Fig. $7 \mathrm{~b}$ whereas the $2-\mathrm{mm}$ thick aorta reached only $10 \%$ loading in the center over the same time frame with the same boundary loading (Fig. 7c). To assess the impact of differential loading, the viability of thin (femoral), average (carotid), and thick (aorta) arteries loaded by the same step protocol was assessed after nanowarming (Fig. 7d). As can be seen, the carotid and femoral arteries (roughly 1-mm thick) had high viability, while the aorta showed low viability. Thus, CPA loading is critical as lower loading leads to lower yields from nanowarming.
One approach to successfully rewarm tissues with less CPA is to increase the warming rate beyond both convection and nanowarming with metal forms. To explore this more generally, the heat generation of copper foams, aluminum foil and nitinol were all predicted and tested. Table 1 summarizes the theoretical SAR predictions based on Stauffer ${ }^{31}$ for a solid rod with a diameter of $.965 \mathrm{~mm}$ heated in an RF system working at frequency of $360 \mathrm{kHz}$ magnetic field intensity of $20 \mathrm{kA} / \mathrm{m}$. The results show nitinol volumetric heat generation at almost six times that of aluminum and copper. Table 2 summarizes the experimental SAR generation for copper foam, aluminum foil and nitinol mesh.

Finally, the viability of warmed carotid artery segments was assessed with varying amounts of CPA loading (Fig. 8a). Importantly, to avoid temperature variations within the artery during ultrarapid warming, the foil was deployed as a sandwich around the artery prior to cooling and warming. After convective warming for DP6-loaded arteries showed a $\sim 35 \%$ 

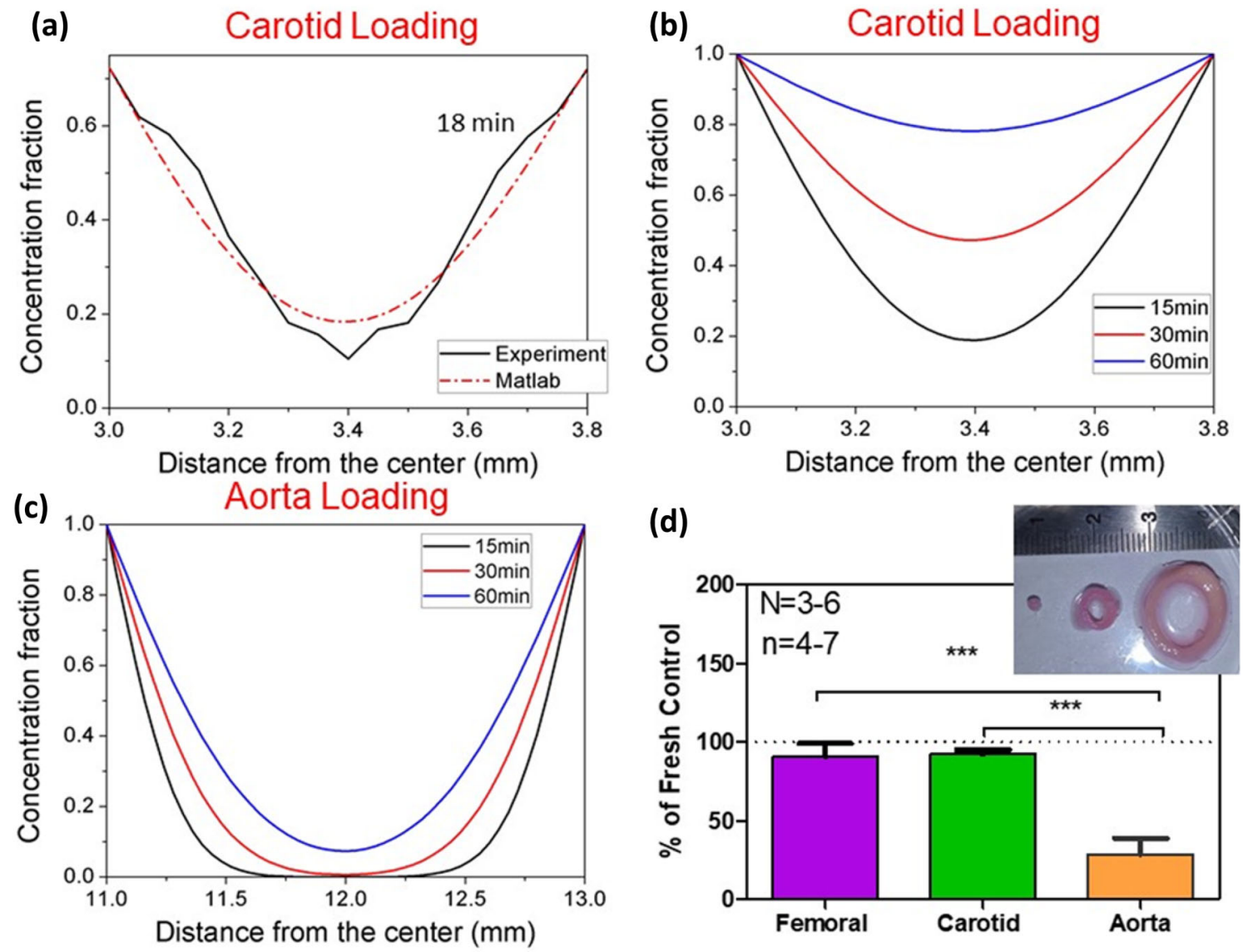

FIGURE 7. Diffusion loading of VS55 with variable rewarming success in arteries. (a) Historical microCT data of VS55 loading into a carotid artery (0.8-mm thick) at $18 \mathrm{~min},{ }^{18}$ used to extract VS55 diffusivity. (b) Predicted temporal and spatial concentration profiles of VS55 with extracted diffusivity and normalized boundary conditions for the same artery at 15, 30 and 60 min. (c) Predicted temporal and spatial concentration profiles of VS55 in thicker $2 \mathrm{~mm}$ aorta at 15, 30 and 60 min. (d) Historical data ${ }^{18}$ post nanowarming in carotid artery and aorta with convection and nanowarming. The viability is reduced for aorta compared to femoral $\left(29 \pm 8.2 \%\right.$ vs. $90.5 \pm 7.4 \%$, $\left.{ }^{\star \star \star} p<0.001\right)$ or to carotid $\left(29 \pm 8.2 \%\right.$ vs. $91.5 \pm 2.4 \%$, $\left.{ }^{\star \star \star} p<0.001\right)$, where $n=3-6$ is the number of independent experiments, and $n=4-7$ is the number of segments tested.

drop in viability vs. VS55-loaded arteries $(p<0.05)$. However, there was no statistically significant viability changes between VS55 or DP6 control arteries after ultrarapid warming. While this demonstrates the ability for ultrarapid warming to recover tissues with suboptimal CPA penetration (i.e., DP6 carotid), it also suggests that ultrarapid warming may work for thicker tissues. To evaluate this theoretically, we varied the heat generation of the warming method in an annular model of an artery as shown in Fig. $8 b{ }^{18}$ Here a baseline volumetric SAR of $2.5 \mathrm{~W} / \mathrm{cm}^{3}$ represents nanowarming. By increasing this SAR by an order of magnitude (i.e., $10 \times$ SAR), one obtains a trend that "arteries" or annular tissues up to 4-mm-thick can be warmed at rates beyond the CWRs of VS55 and DP6. Importantly, these SARs and higher are achievable by deploying the metal forms in the lumen and around the outside of the artery (Table 2). As shown in the Fig. 8c sub-table, CWRs increase rapidly as CPA concentra- tion decreases thereby also showing the need for faster warming techniques such as from metal forms.

\section{DISCUSSION}

This study demonstrates a new approach to increase the warming rates of vitrified biomaterials (solutions or tissues) using inductive heating of thin metal forms. The rates achievable are in excess of $1000{ }^{\circ} \mathrm{C} / \mathrm{min}$ and hence far exceed the critical warming rates of numerous common CPAs. Indeed, the warming rates can be controlled by both choice of metal (type, amount and distribution), and field (frequency and magnetic field intensity) of the RF system. This in turn allows for the eventual rescue of samples that are sub-optimally loaded with CPAs and/or the use of lower concentration CPAs such as DP6. Furthermore, it suggests an opportunity to design the mechanical stress history of 
(a)

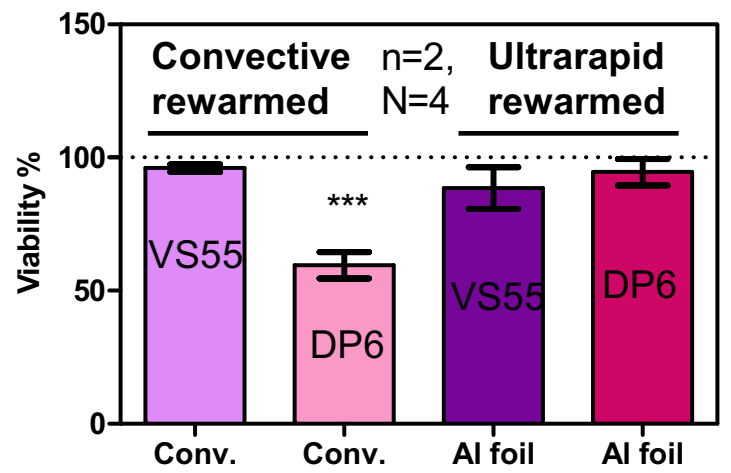

(b)

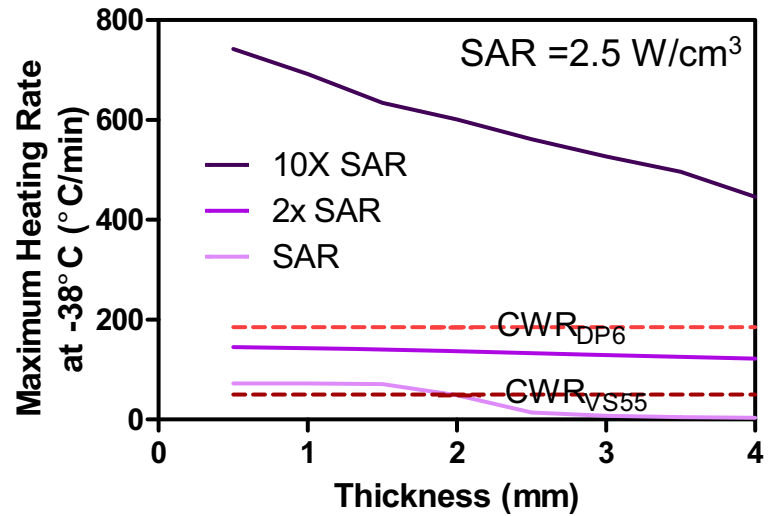

(c)

\begin{tabular}{cccc}
\cline { 2 - 3 } $\begin{array}{c}\text { Properties of exemplary } \\
\text { cryoprotective agents (CPA) }\end{array}$ & $\begin{array}{c}6 \text { Molar } \\
\text { DP6 }\end{array}$ & $\begin{array}{c}\text { 8.4Molar } \\
\text { VS55 }\end{array}$ & $\begin{array}{c}9.4 \mathrm{Molar} \\
\mathrm{M} 22\end{array}$ \\
\cline { 2 - 3 } Critical cooling rate & $-40^{\circ} \mathrm{C} / \mathrm{min}$ & $-2.5^{\circ} \mathrm{C} / \mathrm{min}$ & $-0.1^{\circ} \mathrm{C} / \mathrm{min}$ \\
Critical warming rate & $185^{\circ} \mathrm{C} / \mathrm{min}$ & $50^{\circ} \mathrm{C} / \mathrm{min}$ & $<1^{\circ} \mathrm{C} / \mathrm{min}$ \\
\hline
\end{tabular}

FIGURE 8. Viability of carotid artery segments after convection and ultrarapid warming. (a) Viability was statistically unchanged after ultrarapid warming of VS55 $(88.5 \pm 5.5 \%)$ or DP6 $(94.5 \pm 3.5 \%)$ loaded arteries vs. convective VS55 controls while convectively warmed DP6 loaded arteries $\left(59.5 \pm 3.5 \%, p<0.001^{\star \star \star}\right)$ proved to be $\sim 35 \%$ less effective than VS55 convective controls ( $n=2$ independent experiments and $n=4$ segments per test). (b) Annular model of artery warming with variable SAR and tissue thickness adopted from Manuchehrabadi et al. ${ }^{18}$ Here, a typical volumetric SAR generated from magnetic nanoparticles heating (nanowarming) is given as SAR $=2.5 \mathrm{~W} / \mathrm{cm}^{3}$. This simulation suggests that $10 \times \mathrm{SAR}$, achievable by the ultrarapid method, can warm up to 4-mm-thick arteries if deployed in the lumen and around the artery. Some properties of conventionally used CPA are given in (c).

the sample to avoid cracking failures as recently explored within computational studies of inductively warmed samples. ${ }^{5,29}$

The ability to heat with metal forms is reliant on induced currents in the metal that do not distribute uniformly based on an effect called "skin depth." In practice, over $98 \%$ of the current flow, and thus the bulk of the heating, will occur within a layer four times the skin depth from the surface. Thus, to increase the efficacy of heating, the thickness of the metal forms should be designed as $\geq 4$ times the skin depth at the frequency of tuning. Otherwise the induced eddy currents will cancel each other that results in reduced heating as described further in the Supplemental Material. A summary of skin depth of different metals used in this study is given in Table 1. In brief, metal type, size and shape (i.e., thickness according to skin depth) and frequency of RF field operation are all important in ultrarapid warming.
Although convection is routinely used on small volumes $(<3 \mathrm{~mL}),{ }^{1,2}$ the ability to use convection in larger systems will eventually fail due to cracking as the thermal stress continues to rise with size to be above the yield stress. However, properly designed ultra-rapid warming should be able to achieve uniform and fast warming within a few millimeters from the metal form regardless of the size of the system. This approach is likely to find utility in large-cell suspension or tissues that have lower concentrations of CPA after diffusive loading either due to the lower concentration of the CPA cocktail (i.e., DP6) or due to the increased thickness of the tissue (i.e., aorta).

As an example diffusive loading of VS55 into an artery only $0.8-\mathrm{mm}$ thick achieves only $6 \mathrm{M}$ at the centerline after $3 \mathrm{~h}^{18}$ This physical study was much longer than the conventional loading protocols, which are closer to $75 \mathrm{~min}$ to avoid toxicity. ${ }^{1,2}$ Therefore, in practice, the center of boundary-loaded tissues will likely require faster warming rates than currently 
reported for the CPA alone. This will be particularly important in 2-mm thick aortic tissue (Fig. 7) and other tissues which are routinely $1.5-3.5-\mathrm{mm}$ thick and are known to poorly load with CPA. ${ }^{28}$

Thus, a key advantage of ultrarapid warming is both the low cost of metal forms and the high achievable rates of over $1000{ }^{\circ} \mathrm{C} / \mathrm{min}$. For example, SAR from iron oxide nanoparticles for nanowarming are usually $160 \mathrm{~W} / \mathrm{g} \mathrm{Fe}$ at a cost of dollars/mg nanoparticles, whereas the SAR from metal forms ranges from 80 to $1000 \mathrm{~W} / \mathrm{g}$ at estimated cost for aluminum foil of only cents/g metal. The metal forms can also be designed for easy removal in regular planar (e.g., heart valve, cartilage, suspension) and annular (e.g., artery) geometries.

It is important to mention that the biocompatibility of the metal used in this technique will be important when deployed in large-scale cell suspensions or in proximity to tissue surfaces. Various coating approaches may be needed to address this. Furthermore, although ultrarapid warming technology can be a good alternative for warming of tissues with surfaces and luminal structures, the need for nanowarming for vascularized bulk biomaterial at present cannot be addressed by distributed heating other than by deployment of nanoparticles within the vascular system.

\section{ELECTRONIC SUPPLEMENTARY MATERIAL}

The online version of this article (https://doi.org/10. 1007/s10439-018-2063-1) contains supplementary material, which is available to authorized users.

\section{ACKNOWLEDGMENTS}

We thank the Visible Heart Laboratory's Tinen Iles for access to porcine arteries.

\section{FUNDING}

This work was supported by NSF CBET \#1336659 and the Kuhrmeyer Chair to J.C.B. We are also grateful for the financial support provided by the National Natural Science Foundation of China (11532009) and the National 111 Project of China (B06024). Author contributions: N.M. and M.S. conceived of and carried out experiments with analysis and support from J.C.B. N.M. performed tissue viability work. N.M. and P.R. performed and/or analyzed the heating experiments and thermal and mechanical modeling. N.M. wrote the manuscript with support and input from all the authors.

\section{COMPETING INTERESTS}

Apatent on the ultrarapid warming technology has been published with International Application No. PCT/US2017/018331 and is entitled "Cryoprotection Compositions and Methods." All other authors declare that they have no competing interests.

\section{OPEN ACCESS}

This article is distributed under the terms of the Creative Commons Attribution 4.0 International License (http://creativecommons.org/licenses/by/4.0/), which permits unrestricted use, distribution, and reproduction in any medium, provided you give appropriate credit to the original author(s) and the source, provide a link to the Creative Commons license, and indicate if changes were made.

\section{REFERENCES}

${ }^{1}$ Baicu, S., M. J. Taylor, Z. Chen, and Y. Rabin. Vitrification of carotid artery segments: an integrated study of thermophysical events and functional recovery toward scale-up for clinical applications. Cell Preserv. Technol. 4(4):236-244, 2006.

${ }^{2}$ Brockbank, K. G. M., Z. Chen, E. D. Greene, and L. H. Campbell. Vitrification of Heart Valve Tissues. New York: Springer, pp. 399-421, 2015.

${ }^{3}$ Burdette, E. C., and A. M. Karow. Kidney model for study of electromagnetic thawing. Cryobiology 15(2):142-151, 1978.

${ }^{4}$ Burdette, E. C., S. Wiggins, R. Brown, and A. M. Karow. Microwave thawing of frozen kidneys: a theoretically based experimentally-effective design. Cryobiology 17(4):393-402, 1980

${ }^{5}$ Eisenberg, D. P., J. C. Bischof, and Y. Rabin. Thermomechanical stress in cryopreservation via vitrification with nanoparticle heating as a stress-moderating effect. J. Biomech. Eng. 138(138):1-8, 2016.

${ }^{6}$ Eisenberg, D. P., P. S. Steif, and Y. Rabin. On the effects of thermal history on the development and relaxation of thermo-mechanical stress in cryopreservation. Cryogenics (Guildf) 33(4):395-401, 2014.

${ }^{7}$ Elliott, G. D., S. Wang, and B. J. Fuller. Cryoprotectants: a review of the actions and applications of cryoprotective solutes that modulate cell recovery from ultra-low temperatures. Cryobiology 76:74-91, 2017.

${ }^{8}$ Etheridge, M. L., Y. Xu, L. Rott, J. Choi, B. Glasmacher, and J. C. Bischof. RF heating of magnetic nanoparticles improves the thawing of cryopreserved biomaterials. Technology 2(3):229-242, 2014.

${ }^{9}$ Evans, S. Electromagnetic rewarming: the effect of CPA concentration and radio source frequency on uniformity and efficiency of heating. Cryobiology 40(2):126-138, 2000. 
${ }^{10}$ Fahy, G. M., D. R. MacFarlane, C. A. Angell, and H. T. Meryman. Vitrification as an approach to cryopreservation. Cryobiology 21(4):407-426, 1984.

${ }^{11}$ Fahy, G. M., B. Wowk, and J. Wu. Cryopreservation of complex systems: the missing link in the regenerative medicine supply chain. Rejuvenation Res. 9(2):279-291, 2006.

${ }^{12} \mathrm{Giwa}, \mathrm{S}$., et al. The promise of organ and tissue preservation to transform medicine. Nat. Biotechnol. 35(6):530-542, 2017.

${ }^{13}$ Hahn, D. W., and M. N. Özışık. Heat Conduction. Hoboken: Wiley, 2012.

${ }^{14}$ Incropera, F. P., and D. P. DeWitt. Fundamentals of Heat and Mass Transfer. Hoboken: Wiley, 1996.

${ }^{15}$ Karlsson, J. O. M., and M. Toner. Long-term storage of tissues by cryopreservation: critical issues. Biomaterials 17(3):243-256, 1996

${ }^{16}$ Lewis, J. K., et al. The Grand Challenges of Organ Banking: proceedings from the first global summit on complex tissue cryopreservation. Cryobiology 72(2):169182,2016

${ }^{17}$ Luo, D., C. Yu, L. He, C. Lu, and D. Gao. Development of a single mode electromagnetic resonant cavity for rewarming of cryopreserved biomaterials. Cryobiology 53(2):288-293, 2006.

${ }^{18}$ Manuchehrabadi, N., et al. Improved tissue cryopreservation using inductive heating of magnetic nanoparticles. Sci. Transl. Med. 9(379):eaah4586, 2017.

${ }^{19}$ Mazur, P. Freezing of living cells: mechanisms and implications. Am. J. Physiol. 247(3 Pt 1):C125-C142, 1984.

${ }^{20} \mathrm{Mehl}, \mathrm{P}$. M. Nucleation and crystal growth in a vitrification solution tested for organ cryopreservation by vitrification. Cryobiology 30(5):509-518, 1993.

${ }^{21}$ Noday, D. A., P. S. Steif, and Y. Rabin. Viscosity of cryoprotective agents near glass transition: a new device, technique, and data on DMSO, DP6, and VS55. Cryoletters 49(5):663-672, 2009.

${ }^{22}$ Rabin, Y., M. J. Taylor, J. R. Walsh, S. Baicu, and P. S. Steif. Cryomacroscopy of vitrification, part I: a prototype and experimental observations on the cocktails VS55 and DP6. Cell Preserv. Technol. 3(3):169-183, 2005.

${ }^{23}$ Rachman, M. J. Electromagnetic Warming of Cryopreserved Organs. Cambridge: University of Cambridge, 1990.

${ }^{24}$ Robinson, M. P., and D. E. Pegg. Rapid electromagnetic warming of cells and tissues. IEEE Trans. Biomed. Eng. 46(12):1413-1424, 1999.

${ }^{25}$ Robinson, M. P., M. C. Wusteman, L. Wang, and D. E. Pegg. Electromagnetic re-warming of cryopreserved tissues: effect of choice of cryoprotectant and sample shape on uniformity of heating. Phys. Med. Biol. 47(13):2311-2325, 2002.

${ }^{26}$ Ruggera, P. S., and G. M. Fahy. Rapid and uniform electromagnetic heating of aqueous cryoprotectant solutions from cryogenic temperatures. Cryobiology 27(5):465478, 1990.

${ }^{27}$ Sandby-Møller, J., T. Poulsen, and H. C. Wulf. Epidermal thickness at different body sites: relationship to age, gender, pigmentation, blood content, skin type and smoking habits. Acta Derm. Venereol. 83(6):410-413, 2003.

${ }^{28}$ Shepherd, D. E. T., and B. B. Seedhom. Thickness of human articular cartilage in joints of the lower limb. Ann. Rheum. Dis. 58(1):27-34, 1999.

${ }^{29}$ Solanki, P. K., J. C. Bischof, and Y. Rabin. Thermo-mechanical stress analysis of cryopreservation in cryobags and the potential benefit of nanowarming. Cryobiology 76:129139, 2017.

${ }^{30}$ Stauffer, P. R., T. C. Cetas, and R. C. Jones. Magnetic induction heating of ferromagnetic implants for inducing localized hyperthermia in deep-seated tumors. IEEE Trans. Biomed. Eng. 31(2):235-251, 1984.

${ }^{31}$ Stauffer, P. R., et al. Observations on the use of ferromagnetic implants for inducing hyperthermia. IEEE Trans. Biomed. Eng. 31(1):76-90, 1984.

${ }^{32}$ Steif, P. S., D. A. Noday, and Y. Rabin. Can thermal expansion differences between cryopreserved tissue and cryoprotective agents alone cause cracking? Cryo Letters 30(6):414-421, 2009.

${ }^{33}$ Steif, P. S., M. C. Palastro, and Y. Rabin. Continuum mechanics analysis of fracture progression in the vitrified cryoprotective agent DP6. J. Biomech. Eng. 130(2):21006, 2008.

${ }^{34}$ Steif, P. S., M. Palastro, C. Wan, S. Baicu, M. J. Taylor, and Y. Rabin. Cryomacroscopy of vitrification, part II: experimental observations and analysis of fracture formation in vitrified VS55 and DP6. Cell Preserv. Technol. 3(3):184-200, 2005.

${ }^{35}$ Taylor, M., Y. Song, and K. Brockbank. 22 Vitrification in Tissue Preservation: New Developments. In: Life in the Frozen State, edited by B. J. Fuller, N. Lane, and E. E. Benson. Boca Raton: CRC Press, 2004, pp. 604-641.

${ }^{36}$ Wusteman, M., M. Robinson, and D. Pegg. Vitrification of large tissues with dielectric warming: biological problems and some approaches to their solution. Cryobiology 48(2):179-189, 2004. 